Third International Engineering Systems Symposium

CESUN 2012, Delft University of Technology, 18-20 June 2012

\title{
An Integrated Approach to Strategic Asset Management
}

Kerry Brown ${ }^{1,2}$, Martin Laue ${ }^{1,2}$, Javier Tafur ${ }^{3}$, Muhammad Nateque Mahmood ${ }^{1,2}$, Pascal Scherrer ${ }^{1}$ and Robyn Keast ${ }^{4,5}$

${ }^{1}$ School of Tourism and Hospitality Management, Southern Cross University, Australia ${ }^{2}$ Cooperative Research Centre for Infrastructure and Engineering Asset Management (CIEAM)

${ }^{3}$ Dept. of Industrial Engineering and Business Administration, Universidad Politecnica de Madrid, Spain

${ }^{4}$ School of Management, Queensland University of Technology, Australia

${ }^{5}$ Australian Asset Management Collaborative Group (AAMCoG), Brisbane, Australia

kerry.brown@scu.edu.au, martin.laue@scu.edu.au, Javier.tafur@upm.es, muhammadnateque.mahmood@scu.edu.au, pascal.scherrer@scu.edu.au, rl.keast@qut.edu.au

\begin{abstract}
This paper focuses on identifying and analysing the elements of Strategic Management for infrastructure and engineering assets. These elements are contended to involve an understanding of governance, corporate policy, corporate objectives, corporate strategy and interagency collaboration and will in turn, allow the ability determine a broader and more comprehensive framework for engineering asset management, ie a 'staged approach' to understanding how assets are managed within organisations. While the assets themselves have often been the sole concern for good management practices, other social and contextual elements have come into the mix in order to promote strategic asset management. The development of an integrated approach to asset management is at the base of the research question. What are the considerations and implications for adopting and implementing an integrated strategic asset management (ISAM) framework? While operational matters have been given prominence, a subset of corporate governance, Asset Governance, details the policies and processes needed to acquire, utilise, maintain and account for an organisation's assets. Asset governance stems from the organisation's overarching corporate governance principles; as a result it defines the management context in which engineering asset management is implemented. This aspect will be examined to determine the appropriate relationship between organisational strategic management and strategic asset management to further the theoretical engagement with the maturity of strategy,
\end{abstract}


policy and governance for infrastructure and engineered assets. Asset governance stems from the organisation's overarching corporate governance principles; as a result it defines the management context in which engineering asset management is implemented. The research proceeds by a document analysis of corporate reports and policy recommendations in terms of infrastructure and engineered assets. The paper concludes that incorporating an integrated asset management framework can promote a more robust conceptualisation of public assets and how they combine to provide a comprehensive system of service outcomes.

Keywords. Integrated strategic asset management, service delivery planning, knowledge management, organisational management

\section{Introduction}

Managing assets has become more complex and demanding than ever before due to increasing resource scarcity, degrading environment, climate change, and reliance on multi-agencies. According to Brown and Humphrey (2005), asset management is based on three main pillars: management, engineering and information, which together form a foundation for efficient and/or sustainable use. The degree of functionality of any asset is dependent on how well it is planned, designed, operated, maintained, and disposed in the context of these three core areas. As a counter to these challenging tasks, instead of managing assets through a whole-of-life cycle approach by individual agencies/organisations, there has been a shift towards a more integrated or collective approach involving multi-agencies/organisations. Such an approach allows organisations to access additional knowledge, expertise and resources to create collaborative advantage. This approach is not business as usual and necessarily requires a shift in the way in which infrastructure projects are developed, delivered and managed. Therefore, in this paper, we developed more comprehensive framework for asset management in order to fit in a multi-agency environment, new contextual considerations and contemporary approaches to managing built assets.

\section{New Issues in Asset Management}

Previous asset management models while useful in their context are no longer sufficient or adequate to meet the changing nature and challenges of contemporary society. This paper incorporates and extends a previous framework for asset management (Australian Procurement and Construction Council, 2001; Western Australia Department of Treasury and Finance, 2010; New South Wales Treasury, 2004). Drawn from (literature and workshops) a number of additional elements which are contended to be important for inclusion to be considered:

Environmental: Greater appreciation of the interaction between built assets and the natural environment. 
Sustainability: Ensures that the social, economic and environmental needs of a community are met and kept healthy for future generations (Sustainability Victoria, 2010).

Resilience: Increased emphasis on the asset, environment and the community to respond to and recover from external impacts.

Whole of life asset management: Requires that decisions and actions across the entire lifecycle of the asset from design to disposal be considered.

Increased community demands: information and communication technology (ICT) advances have led to higher citizen expectations for immediate and localised services. Closer alignment of policies, resources and projects will deliver better quality, more efficient and timely built assets.

Information management: Information needs and capabilities are more demanding and complex.

Expanded governance arrangements: Assets are now owned, governed and operated by an expanded set of decision-makers. Alongside conventional governance forms, there is now an array of hybrid models such as public-private partnerships, alliance and relational contracts. More innovative and variable governance approaches are required for these different models to manage the unique risks and opportunities associated with them.

\section{Integrated Strategic Asset Management Framework}

The following framework pulls together the expanded elements and reflects the increasingly complex and interconnected processes which government and its agencies need to take into account when delivering services. The framework demonstrates that ISAM as shown in Fig.1, is cumulative and each component is interdependent. 


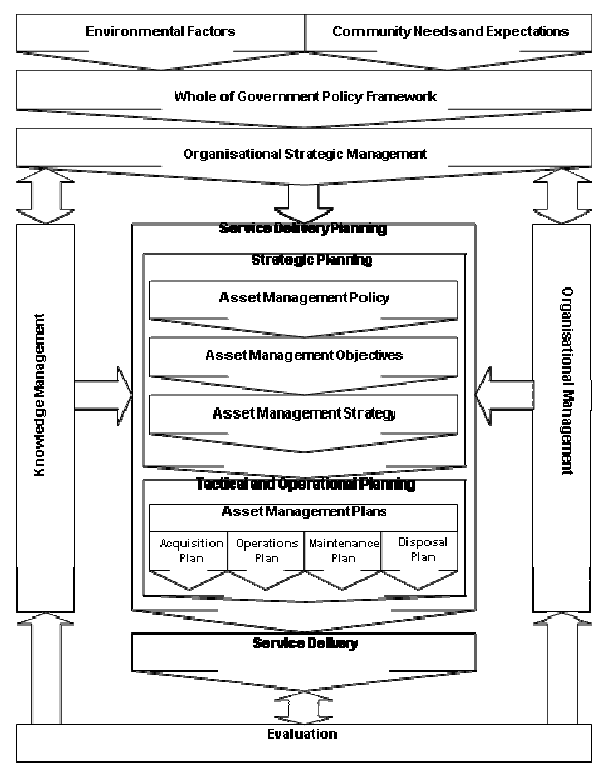

Fig. 1. Integrated strategic asset management framework

A logical progression through each component is required for maximum service delivery outcomes. Whilst this ISAM framework focuses on the public sector, it is equally applicable to any organisation or sector. The development of the ISAM framework is based on the current literature review including journals, conference papers and reports from different government and private organisations, and also from opinions/feedback of experts in the field of asset management. The following sections in this paper explain each part of the framework in more detail.

\subsection{Environmental Factors}

This section provides additional information related to environmental factors affecting asset management, in particular it focuses on risk management and sustainability management.

Risks arise as a result of two main areas: a limited, or lack of, knowledge, experience or information and uncertainty (particularly about the future); or as a result of relationship changes between the parties involved in an undertaking (New South Wales Treasury, 2004). The aim of Risk Management is to achieve more reliable planning, greater financial certainty and improved decision making and management outcomes. Risk Management should be applied on all governmental (Government and Agency) and organisational (Strategic Management and Asset Management) levels. It provides planners and managers with a structured way of identifying and analysing 
potential risks, and assists in devising and implementing appropriate strategies to help mitigate risks, considering their likely impact. Strategies can include risk prevention, risk transfer, impact mitigation or risk acceptance. A range of strategies can be used within a single project for a number of anticipated individual risks.

Sustainability Management is the ability to meet present needs without limiting the ability of future generations to meet their own needs (Australian Procurement and Construction Council, 2007). Sustainability Management has a significant impact on policy development and strategy considerations. As a result it is vital that private and public organisations take Sustainability Management issues into consideration when developing policies and strategies. A core concept in Sustainability Management is the notion that there is interdependency between human communities and economies - in other words the way in which humans manage the environment is linked with the level of community cohesion and its economic performance.

\subsection{Community Needs and Expectations}

This section outlines Community Needs and Expectations. In particular, it provides a framework for understanding the requirements of the community and suggests that a range of stakeholder engagement strategies may assist Asset Managers in effective stakeholder management practices.

In the context of public sector, Asset Management 'demand' refers to community and government needs and expectations. It also encompasses the ambitions and aspirations of other sectional groups. As the driving force for supply, community/government needs and expectations, and sectional groups' aspirations and ambitions are all key inputs into the Asset Management process (New South Wales Treasury, 2004).

However, demand can outstrip supply in the case of government services - often as a result of limited financial resources. In consequence, managing demand is critical to ensure priorities are appropriately identified and met so as to ensure maximum community benefit. Demand Management helps to achieve this; in essence it involves active intervention in the market to influence demand for services, including assets (Australian Procurement and Construction Council, 2001).

Stakeholder Management is the process of interpreting the expectations of external and internal individuals or groups, who have an interest in asset management activities or will be effected by its outputs and the process of interacting with them. The objective of Stakeholder Management is the creation of a positive relationship with different stakeholders and comprises stakeholder identification, stakeholder classification, strategy development, stakeholder engagement, and of the maintenance of relationships (Beach and Keast, 2010).

\subsection{Whole-of-Government Policy Framework}

Limited resources mean governments have to exercise sound financial, social and environmental management and make prudent decisions to best prioritise services to meet community needs and expectations. This service delivery approach is achieved 
through a whole-of-government model, which is comprised of legislation, policies, plans, service delivery strategies and standards, capital and recurrent budgets and, government institutions; and partnerships including with working groups, community based organisations and private providers. This framework is designed to guide a coherent service intervention model and assist effective and accountable service delivery across all levels of government as well as within the private and community sectors.

\subsection{Organisational Strategic Management}

Organisational Strategic Management gives effect to whole-of-government policy through service delivery. The organisation is responsible for delivering the service; therefore it needs to determine how this should occur and what is required. Organisational Strategic Management involves an understanding of governance, corporate policy, corporate objectives, corporate strategy and interagency collaboration. Asset Management Strategic Planning should be aligned with and stem from the Organisational Strategic Management objectives to ensure smooth and effective management of company's assets and service delivery. The main components of organisational strategic management are Governance, Corporate Policy, Vision and Vision Statement, Mission and Mission Statement and Values.

Governance: Alles et al. (2005) define governance as "the laws, policies, and procedures that ensure organisations run in the interest of owners and resources are allocated, managed, and redeployed to maximize productivity and value". Governance helps to determine the correct management processes, organisational structures and incentives are employed to ensure managerial attitudes and behaviours align with key stakeholder interests (Jensen and Meckling, 1976) as well as to determine the appropriate reporting and disclosures that ensure transparency and accountability (Dunis and Miao, 2006). For this ISAM framework, the Governance can also be specified as Corporate Governance.

The framework by which companies are directed and managed is referred to as Corporate Governance. Corporate Governance encompasses how an organisation's objectives are set and realised, how risk is monitored and measured, and how its performance is optimised. Good corporate governance encourages organisations to create value through innovation, entrepreneurism, development and exploration; provides accountability; and ensures there are control systems in place appropriate to the level of risk.

A subset of corporate governance, Asset Governance details the policies and processes needed to acquire, utilise, maintain and account for an organisation's assets (Cornish and Morton, 2001). As such, asset governance can be considered to be an asset management approach that encompasses asset ownership and the management of distributed systems in a competitive and deregulated market (Bühner, 2000; Considine and Lewis, 2003; Gomez, 2004; Narracott and Bristow, 2001; Schmidt and Brauer, 2006).

Asset governance advocates transparent and accountable asset management policies. It outlines aims to define principles to manage assets effectively in distributed 
networks, a context where the development, stewardship and operation of assets may be open to competition (Kitchen, 2006). Central to good asset governance is the clear definition and differentiation of roles and responsibilities, particularly those of the asset owner, asset governor and service providers (Cornish and Morton, 2001). As such, asset governance provides for a micro level mechanism to manage the separation of powers in asset management that typifies network management (Moore, 1993), and facilitates effective asset management in a distributed system. Regulatory compliance, supply business satisfaction, risk-based, data supported, continuous improvement, pragmatic, and income maximisation and generation are all key asset governance principles.

Asset governance stems from the organisation's overarching corporate governance principles; as a result it defines the management context in which engineering asset management is implemented (Mardiasmo, 2008).

Corporate Policy: To constitute the fundamental purpose of an organisation, its intentions and ideals for a future direction, it is necessary to develop and state a Vision, a Mission and organisational Values (summarised in the Corporate Policy). These factors are needed within an organisation to have a common goal, in which the employees can believe, and to which they can work towards. These factors are also needed to inform the public about the organisation's goals and intentions.

Vision and Vision Statement: The Vision encapsulates an organisation's future direction and business constitution and describes an ideal to be strived. It acts as a guide for what the organisation is striving to achieve and become. A strategic Vision focuses on the organisation's future (Thompson and Stickland, 1999). The Vision is formalised and documented in the Vision Statement. Many organisations today develop a Vision Statement that answers the question "What do we want to become?" (David, 2009). Whereas the focus of the Corporate Vision is on the future direction, the organisation's Mission tends to focus on the present, answering "What is our business and what are we trying to accomplish on behalf of our customers?" (Thompson and Strickland, 1999). It comprises the organisation's reason for existence, its fundamental purpose and includes its character and values (Viljoen and Dann, 2000).

Mission and Mission Statement: The Mission is formalised and documented in the Mission Statement. The Mission Statement encompasses the organisation's activities and current business constitution (Thompson and Strickland, 1999) answering "What is our business?" (Viljoen and Dann, 2000).

Values: Underpinning business activities are an organisation's values — guidelines that regulate the behaviour of staff and management as they endeavour to achieve the organisation's Vision (Viljoen and Dann, 2000). The organisation's values can be assessed based on the Corporate Objectives, Corporate Strategy and Interagency Collaboartion.

Corporate Objectives are developed by organisations in order to articulate what the organisation hopes to achieve in the future. They act as a guide for all organisational activities and projects in order to ensure the organisation's long-term success and viability, and must be flexible in order to respond to the internal and external 
environment. Corporate Objectives are a culmination of a range of strategic analyses and are derived from the organisation's mission, capabilities and resources; PEST and SWOT analyses; community demands; government objectives; and desired outcomes.

According to Viljoen and Dann (2000), "Corporate Strategy refers to the management of the entire organisation and concerns how the Mission is activated to achieve the Corporate Objectives". In particular, Corporate Strategy encapsulates how an organisation's activities align with its mission and values to ensure its long-term prosperity. Strategies are future-focused, requiring top management decisions and organisational resources. Strategies affect the long-term prosperity of an organisation and are multi-functional and multi-divisional, and must take into account the internal and external environment. Given their impact, choosing appropriate strategies is critical and all options should be carefully identified and considered before a preferred option is chosen (David, 2009). In developing Corporate Strategy, risk management should be applied in order to ensure that corporate objectives are met, risk consequences do not adversely impact any stakeholders and the best strategic planning strategies are chosen (New South Wales Treasury, 2004).

Interagency collaboration involves representatives from various agencies coming together to identify and work toward a common goal. Collaboration is defined as "...a process to reach goals that cannot be achieved acting singly (or, at a minimum, cannot be reached as efficiently). As a process, collaboration is a means to an end, not an end in itself" (Bruner, 1991). During interagency collaboration, problems and solutions are shared across agencies with the common method for achieving set objectives being consensus building using an action-planning format. Another characteristic of interagency collaboration is the merging of resources including funding sources, training and personnel, as well as program philosophy (Keast et al., 2004). In order to achieve the intended group outcome, group members agree to disagree in order to focus on the collaboration target at hand.

\subsection{Service Delivery Strategic Planning}

Service delivery is indicated by the Level of Service (LOS) provided by an asset. A Service Delivery Strategy translates the broad aims of an organisation into specific service outcomes. It clearly outlines the plans to deliver services and the overall strategy that will be adopted to satisfy community needs and obtain value for money. There are multiple vehicles to deliver a service, ranging from non-asset solutions including contracted services supplied by external parties, the re-use of existing assets to the provision of a new asset. Service delivery strategic planning can be described under the following three headings.

Asset Management Policy: An Asset Management Policy is the translation of the Corporate Strategy for the process area of Asset Management; as such it is based on the Corporate Policy and Corporate Objectives. It has to be consistent with the Government Policy Framework and the Government Objectives, and has to help to satisfy the Community Demands. An Asset Management Policy is the overall basis of all Asset Management decisions and activities and, like the Corporate Policy, it includes a Vision and a Vision Statement, a Mission and a Mission Statement, and Principles for the area of Asset Management. 
Asset Management Objectives: Asset Management Objectives are indicators for the implementation of the Asset Management Policy and the achievement of the Asset Management Strategy. They are derived from the Government Objectives and Corporate Objectives and on a functional level they can relate to the required performance or condition of an asset. Asset Management Objectives should detail how each objective will be measured over a period of time in order to evaluate the organisation's performance - without this, objectives will only be a 'wish list'. According to Viljoen and Dann (2000) objectives should include: the attribute to be measured (e.g. share of market, or customers/clients serviced), the scale on which the attribute is to be measured, referred to as a 'yard stick' (e.g. percentage points), a goal (level of the attribute desired), a specified period of time to achieve the goal.

Asset Management Strategy: The Asset Management Strategy (Agency's Service Delivery Strategy) follows the specifications of the Asset Management Policy and sets out activities, which help to achieve the Asset Management Objectives. In essence it also supports the Corporate Strategy and the achievement of the Corporate Objectives. How an agency's Asset Management responds to Community Demands is guided by the Asset Management Strategy which outlines the development of an asset portfolio, risk management strategies and asset performance measures. According to the New South Wales Treasury (2004), the Asset Management Strategy identifies any requirements needed ('gaps') to support services and outlines the organisation's response to these by identifying appropriate acquisitions (planned capital investment), maintenance and disposal (such as replacement and/or upgrading).

\subsection{Service Delivery Tactical and Operational Planning}

Service Delivery Tactical and Operational Planning is also known as Asset Management Planning, which specifies how assets have to be managed to fulfil the Asset Management Strategy to achieve the Asset Management Objectives. In order to do so, Asset Management Plans set out a framework for an organisation to allocate appropriate resources and make strategic decisions to support service delivery through the whole asset management life cycle. Asset Management Plans should be comprised of four plans (acquisition plan, operations plan, maintenance plan and disposal plan) and they are described as follows:

Acquisition Plan: An Acquisition Plan is the primary document outlining the acquisition of all major assets. It also links program delivery needs to the required assets. The Asset Management Strategy facilitates asset acquisition decisions, while business plans are used to consider various alternatives such as non-asset solutions and the use of other assets within the existing asset portfolio. There are a number of ways to acquire assets: purchasing, construction, development, finance lease. For significant acquisitions, (those that are complex and/or involve significant cost), detailed plans are prepared. These plans can include: a statement of need and acquisition rationale, staff roles and responsibilities required to manage the acquisition, required acquisition activities such as contract management and other technical, legislative and management considerations, timeframes and the key decision points throughout the acquisition plan, capital outflows amounts and timing, 
anticipated life-cycle costs, monitoring and other control processes to ensure the intended acquisition outcome (Australian National Audit Office, 2010).

Operations Plan: The operational aspects of an asset based on its life-cycle are detailed in the Operations Plan. Operations Plans detail the program and asset manager roles and responsibilities, and assign responsibility for asset performance and life-cycle cost accounting including: asset performance measures, asset condition, physical security and safeguarding, depreciation, finance costs, operating costs for example energy and cleaning costs, specialist staff costs required to operate an asset, operational training costs, maintenance costs, major disposal costs for example, make good, demolition or restoration (Tasmania Department of Treasury and Finance, 2004; Australian National Audit Office, 2010).

Maintenance Plan: Research shows that poor maintenance can result in a loss of functionality; a shorter than anticipated useful life; reduced utilisation; or even result in a threat to human safety or a breach in legislative requirements. As such it is a critical function in the overall life-cycle of an asset (Australian National Audit Office, 2010). Maintenance has a dual purpose: refurbishment (restoring an asset to a required benchmark enabling its useful life) and enhancement (increasing an asset's service potential). Maintenance planning is key - particularly for major maintenance activities requiring critical assets to be taken off-line. Maintenance involves a range of activities and can be broken down into planned and unplanned operations and recurrent maintenance, and major and minor capital works.

Diposal Plan: The Disposal Plan leads into the planning process for new or replacement assets and is a useful management tool in assessing why assets may not have performed as intended. As such it should be an integrated part of the Asset Management Strategy. A number of reasons for disposing an asset can be identified including: end of useful life; surplus to requirements; under-utilised; not fit for purpose; unserviceable; the need for the service provided by the asset has disappeared; does not meet legislative requirements. The Australian National Audit Office (2010) identifies a number of considerations when planning significant asset disposal: rationale for disposal, the proper costing and evaluation of disposal alternatives, engagement of experts to assist in professional valuation and disposal, due diligence reviews to ensure there is sufficient transparency and accountability for asset disposals including compliance with legislative requirements, proper approval authority, both within and outside the entity where required.

\subsection{Service Delivery}

Service delivery comprises the actual provision and maintenance of services, in accordance with the strategic and tactical plans, and the operational management. Service delivery activities would generally comprise the creation, maintenance, renewal/upgrading and disposal of the assets but may also include operational activities. For example a building comprising an aquatic centre would require ongoing expenditure on maintenance and upgrade of facilities as well as expenditure on operating activities such as staff, chemicals and utilities. For optimal service delivery clear assignment of responsibility and accountability should be established for each 
asset and its related operations. This includes the identification of assets, the capture of information and the assessment of performance against the agreed level of service.

\subsection{Evaluation}

Evaluation is the measuring, reporting and reviewing of asset performance against asset management, organisational and government objectives. Contemporary evaluation now incorporates not only the evaluation of the asset but also the evaluation of the impact of the asset on the environment and society. The following information is provided in relation to the Evaluation function: Asset Performance Measurement, Review, Audit and Report.

Asset Performance Measurement: In addition to ensuring that an organisation's actions, objectives and strategies align, "the goal of a performance measurement system is to communicate and implement strategy" (Kennerley and Neely, 2003). As a result, performance measurement systems and frameworks need to reflect efforts to measure how activities and processes: contribute separately and jointly to meet Asset Management and Corporate Objectives; link operations to strategic goals; ensure a customer focus; drive future activities and needs; and enhance performance (Cross and Lynch, 1989). Performance measurement should provide meaningful measures of activities, processes and achievements as well as facilitate stakeholder feedback (Hyland et al., 2009). Asset Performance Management identifies and registers all assets required to deliver the stated service and determines how effectively and efficiently these assets support the service requirements. A number of performance measures exist to assess asset performance: Financial Performance, Function, Utilisation and Physical Condition (AAMCoG, 2008).

Many asset owner organisations now adopt Key Performance Indicators (KPIs) to measure performance, identifying what the organisation sets out to achieve in terms of service levels and sets KPIs for those services. Recording and analysing KPIs significantly contributes to achieving Corporate and Asset Management Objectives. In essence, KPIs identify how well services are provided, and how much time is taken to address and correct performance gaps between intended and actual performance. As defined by AAMCoG (2008), "Key Performance Indicators are those critical performance measures which ultimately determine assets serviceability and stakeholder value" and can be: process-based (e.g. statutory compliance), activitybased (e.g. dollars spent) and, outcome-based (e.g. goals achieved, service success).

KPIs are particularly useful when they link to policy concerns or outcomes. KPIs fall into a number of categories, such as: quantitative (the amount of a product or service), qualitative (structured perceptions or structured feedback), cost efficiency (the unit cost of achieving a specified amount of service), cost effectiveness (the unit cost of achieving a specified amount of service to a designated level of quality), timeliness/responsiveness (the time taken to perform a service, or the number of transactions or products within a time cycle), and work team productivity (the output of a workforce unit or group) (Vial and Prior, 2003).

Management Reporting: Reports can be distinguished by progress reports, benefit reports, and financial reports. 
Regular progress reports should be provided to senior agency decision-makers, Ministers and Cabinet, covering: important milestones, including whether delivery is proceeding on time and meeting budget; whether project start-up was achieved in line with the endorsed costs and schedule; any serious emerging problems that are likely to affect service benefits articulated in the business case, and for which support for potential responses may be needed (such as additional maintenance to address unexpectedly high usage rates, or negative variations in the performance of contractors) (Western Australia Department of Treasury and Finance, 2010).

Benefit reports inform future decision-making, strategic asset investment planning, business case development, and Asset Management and are required as part of an agency's senior decision maker's Asset Management responsibilities. The Benefit Report should be provided at appropriate intervals throughout a major asset's lifecycle and should: clearly state the extent to which value for money from the asset is being achieved compared to the predicted results, highlight any lessons learned to be later incorporated into planning for similar assets, or in business cases relating to the asset later in its life (e.g. to clarify whether an asset should be refurbished or should be subject to disposal). After disposal, senior decision makers should be advised on the total value for money and service delivery benefits gained from the investment.

Financial reporting (also referred to as 'close the books') is the process of reconciling, consolidating and generating financial reports/statements periodically to meet regulatory requirements and the information needs of internal and external stakeholders (Australian National Audit Office, 2002; Department for Victorian Communities, 2006). According to the Australian National Audit Office (2002) financial reporting activity can include: ensuring validity and consistency in the organisation's charts of accounts; , completing journal entries; consolidating data from outlying business units; running trial balances; correcting errors; reconciling and analysing accounts; calculating taxes; preparing and distributing reports; supervising closing tasks; and reviewing key accounts and reports.

Review: As outlined by the Queensland Department of Environment and Resource Management (2010), reviews allow organisations to adopt a strategic view of: performance in relation to service levels; operation, maintenance and renewals; future demands/ flows; and other factors impacting on its future service levels and standards; and whether the strategies, actions and financial projections are optimal.

There are two categories of reviews: Post Implementation Review (assesses how well the project outcomes aligned with the actual needs the project aimed to meet) and Post Completion Review (a method of systematically and rigorously comparing actual project performance with the original project objectives). Reviews are normally carried out internally by the service provider; however external consultants may be employed. Regardless of whether the review is carried out internally or by an external contractor, key service provider personnel, such as field staff, must be involved in the review process. Reviews should be seen as a predecessor to regular audits.

Audit: "An audit is a systematic, independent and documented process for obtaining evidence and evaluating it objectively to determine the extent to which the audit criteria, the standards and obligations in a service provider's policies, procedures or 
requirements, have been fulfilled" (New South Wales Treasury, 2004). Audits form part of the regulatory framework, verifying that service provider information is accurate and reliable. Audits also provide evidence to customers and stakeholders that services comply with regulatory requirements. In addition to benefiting the agency, audits also benefit service providers, identifying improvement opportunities and providing incentives to achieve compliance.

The auditing process relies on a number of key principles to ensure that relevant and appropriate conclusions are reached. They also enable independent auditors to reach similar conclusions in similar circumstances. These principles ensure audits provide effective and reliable support to management policies and controls, by providing information on which an organisation can assess and act upon to improve service performance.

\subsection{Knowledge Management}

This section focuses on knowledge management practices, which can assist in increasing asset productivity. In particular, it provides valuable insights related to the development and maintenance of asset information repositories, such as asset registers and offers suggestions for improving the acquisition, sharing and integration of tacit knowledge. Knowledge management is a systemic and organisationally specified process for acquiring, organising, and communicating both tacit and explicit knowledge so that others can use that knowledge to become more effective and productive (Alvi and Leinder, 2001; Love and Irani, 2005). According to Leng nad Stepherdson (2000), there are different benefits of Knowledge Management:

Effectiveness (better access to expertise and past learning experiences can lead to improved decision making);

Responsiveness (an integrated knowledge of customers' preferences and needs can improve an organisation's responses);

Efficiency (the reuse and transfer of knowledge can enhance the productivity of knowledge workers);

Flexibility (knowledge enables organisations to be more flexible and responsive to rapid changes in the market as a result of better insights on customer and competitor trends; and

Innovation (knowledge assists in the successful designing of new products, services and processes faster and with greater frequency).

One way to ensure effective, asset related, knowledge management is through the application of data and information management systems, which have become essential for most business operations, providing quality and timely data for decision makers. Information systems now cover a range of Asset Management areas such as asset registration; process scheduling and control; materials, maintenance, risk, reliability, and safety management; and condition monitoring (Mathew and Hargreaves, 2008) 
Asset Registers house information relating to various aspects of an asset portfolio, allowing it to be cross-referenced and retrieved as needed. Assets that have service potential and/or the capacity to provide economic benefits through their use in service delivery should be recorded in an asset register. Asset Registers come in many forms and can be electronic (e.g. computer) or paper-based (e.g. card file). Data can relate to one or more categories including: service delivery functions; physical properties; technical data; financial information (e.g. asset valuation and expenditure); property title details, key operational data, maintenance data and, performance records. Asset Registers should be integrated into the agency's management information system. While agencies have different needs a consistent approach can be adopted.

Asset Data Management concerns the capture, management and utilisation (data acquisition, data analysis, and information use) of asset data. The resulting translated data is essential to improve asset reliability, safety, availability, utilisation and an increased return on investment.

\subsection{Organisational Management}

Organisational management is the process of planning, organising, leading and controlling the efforts of organisation members and resources to achieve organisational goals. From the asset management perspective, organisational management involves support for strategic asset management through effective leadership. It may also involve shaping and auditing organisational competencies and skills, adopting change management strategies, and promoting asset management culture to ensure optimal asset management outcomes.

Leadership: Leadership quality directly impacts the successful implementation of any Corporate or Asset Management Strategy. Leadership involves supervising activities, giving orders and motivating subordinates in a way that meets the corporate and asset management objectives. These leadership functions can be classified as one of three main management functions: planning, organising and leading. The main activities as identified by Luffman et al. (1996) are: planning (investing, evaluating, decisionmaking and controlling); organising (organising the structure, staffing, communicating, co-ordinating, negotiating, representing); and leading (supervising, giving orders and motivating).

A Strategic Asset Manager is responsible for a range of activities carried out over an asset's life-cycle, including: planning, designing, developing, operating, maintaining, rehabilitating, retiring and disposing different types of physical assets technically and economically, as well as in a socially responsible and sustainable way. They must consider the short- and long-term life-cycle to satisfy the needs of not only today's generations but future generations and focus on the bigger picture as well as more micro operational issues.

Change Management: In a change management context, change is a broad occurrence involving the growth and/or development of one or more public service elements, such as: service design; organisational structure; organisational culture; the management or administration of the organisation; and the skills needed to manage and deliver the service. Planned change management involves systematically 
scanning the environment and determining ways in which an organisation must adapt or change. Planned change involves four stages:

1).Setting goals and defining the 'desired future state';

2). Diagnosing the present condition in relation to these goals and setting the desired future state;

3). Defining the transitional activities and commitments needed to achieve the desired future state; and

4). Developing strategies and an action plan to manage the transition and reach the desired future state (Adapted from Beckhard, 1969).

To develop effective change strategies, agencies must set clear corporate objectives, adopt appropriate communication strategies and linkages across the agency and possess high-quality leadership and management. According to Osborne and Brown (2005), "Emergent change management is the reaction to change that is thrust upon an organisation by changes in its environment that are outside of its control". To respond to emergent change, managers must be enablers of organisational learning, specifically learning and developing by trial and error, and must also create an environment where staff can also learn from their experiences.

Organisational Competencies and Skills: Competence refers to the knowledge and skills a person possesses or is required to posses in order to perform a work activity. Organisations need to constantly audit their current skill sets to identify gaps and the resources required. McGeoch et al. (2011) stress the importance of asset management related training to ensure qualified personnel, who are clear about their role and accountable for their performance. Within a work context, required knowledge and skills include the areas of: organisation, process, work task and working environment; and can be categorised as professional, social, or methodical competence.

Asset Management Culture: Osborne and Brown defined Organisational Culture as "the shared ideas, customs, assumptions, expectations, traditions, values and understandings that determine the way employees will behave." An organisational ethos that promotes optimal asset management outcomes often requires significant and deliberate cultural change. Pushing cultural boundaries may be necessary to embed a sustainable asset management culture.

\section{Conclusion}

Integrated strategic asset management has never been more crucial or challenging. Modern societies rely on a well connected system of purposeful and functional assets to maximise their wellbeing. Economic modelling demonstrates that developing and replacing existing and often aging public assets is an increasingly expensive process; drawing on already constrained budgets. Coupled with this economic imperative is a growing appreciation of the importance of embedding a consideration of the sustainability of the environment in which assets are located. Together these elements call for a more holistic conceptualisation of infrastructure and engineering assets and 
how these different elements combine to provide a comprehensive system of service outcomes. The ISAM framework has been developed from the benchmarks in industry, international best practice and leading edge research.

This paper explores a contemporary set of practices to assist those responsible for the delivery and management of assets. Rapid advances in knowledge and technologies mean that asset management practice, and therefore this ISAM framework, will be subject to continued evolution and change.

\section{References}

AAMCoG (2008): Public Sector Asset Performance Measurement and Reporting, Australian Asst Management Collaborative Group (AAMCoG) and Cooperative Research Centre for Integrated Engineering Asset Management (CIEAM)

Alavi, M., \& Leidner, D. (2001). Review: Knowledge management and knowledge management systems: Conceptual foundations and research issues. MIS Quarterly, 25(1), 107-136.

Alles M G, Datar S M, Friedland J. H. (2005): Governance-linked D\&O Coverage: Leveraging the Audit Committee to Manage Governance Risk, International Journal of Disclosure and Governance, vol. 2, pp. 114-129, June 2005. In: Mardiasmo D, Tywoniak S, Brown K, Burgess K (2008): Asset Management and Governance - An Analysis of Fleet Management Process Issues in an Asset-intensive Organization. In: International Conference on Infrastructure Systems: Building Networks for a Brighter Future, 10 - 12 November, Rotterdam, Netherlands

Australian Procurement and Construction Council (2007) Australian and New Zealand Government Framework for Sustainable Procurement.

Australian Procurement and Construction Council (2001) Asset Management.

Australian National Audit Office (2002): Benchmarking the Finance Function Follow-on Report - Benchmarking Study

Australian National Audit Office (2010): Better Practice Guide on the Strategic and Operational Management of Assets by Public Sector Entities - Delivering agreed outcomes through an efficient and optimal asset base

Beach S, Keast R (2010) Governance networks and stakeholders: engaging through salience. In 14th Annual Conference of the International Research Society for Public Management (IRSPMXIV), 7-9 April 2010, Bern, Switzerland

Beckhard R (1969) Organization Development - Strategies and Models. Reading, Massachusetts. Addison-Wesley Publishing Company. In: Osborne S P, Brown K (2005): Managing Change and Innovation in Public Service Organizations, Routledge

Brown RE and Humphrey G (2005). Asset management for transmission and distribution. IEEE Power Energy Magazine 3(3): 39-45.

Brown K, Burgess K (2008): Asset Management and Governance - An Analysis of Fleet Management Process Issues in an Asset-intensive Organization. In: International Conference on Infrastructure Systems: Building Networks for a Brighter Future, $10-12$ November, Rotterdam, Netherlands 
Bruner C (1991): Thinking Collaboratively: Ten Questions and Answers to Help Policy Makers Improve Children's Services. Washington, D.C.: Education and Human Services Consortium. p.6. In: California Department of Education (2007): Handbook on Developing and Evaluating Interagency Collaboration in Early Childhood Special Education Programs. p.168

Bühner R (2000): Governance Costs, Determinants, and Size of Corporate Headquarters, Schmalenbach Business Review: ZFBF, vol. 52, p. 160, Apr 2000

Considine M, Lewis J M (2003): Bureaucracy, network, or enterprise? Comparing models of governance in Australia, Britain, the Netherlands, and New Zealand, Public Administration Review, vol. 63, p. 131, Mar/Apr 2003

Cross K F, Lynch R L: (1989) The Smart Way to Define and Sustain Success. National Productivity Review, 9(1). In: Hyland P, Ferrer M, Santa R, Bretherton P (2009): Performance measurement and feedback in a public sector program, In: Soosay C, O'Neill P, Prajogo D (Eds.): Proceedings of the 7th ANZAM Operations, Supply Chain and Services Management Symposium, 8 - 10 June, Adelaide, Australia

David F R (2009): Strategic Management: concepts and cases, 12. Edition, Pearson Education

Department for Victorian Communities (2006): Guidelines for Measuring and Reporting the condition of Road Assets

Dunis C, Miao J: Volatility filters for asset management: An application to managed futures, Journal of Asset Management, vol. 7, p. 179, Sep 2006. In: Mardiasmo D, Tywoniak S, Cornish N, Morton K (2001): Asset Governance - A Radically New Way to Manage Distribution Networks in a Competitive and Deregulated Market. In: 16th International Conference and Exhibition on Electricity Distribution (CIRED 2001), Amsterdam, Netherlands, 2001

Gomez P Y (2004): La gouvernance de l'entreprise, Revue Française de Gestion, vol. 30, p. 249, Jan/Feb 2004

Hyland P, Ferrer M, Santa R, Bretherton P (2009): Performance measurement and feedback in a public sector program, In: Soosay C, O'Neill P, Prajogo D (Eds.): Proceedings of the 7th ANZAM Operations, Supply Chain and Services Management Symposium, 8 - 10 June, Adelaide, Australia

Jensen M C, Meckling W H: Theory of the Firm: Managerial Behaviour, Agency Costs, and Ownership Structure, Journal of Financial Economics, vol. 3, pp. 305-360, 1976. In:

Keast, R, Mandell, M, Brown, K and Woolcock, G. (2004) Network Structures: Working Differently and Changing Expectations, Public Administration Review 64 (3) 353-361

Kennerley M, Neely A (2003): Measuring Performance in Changing Business Environment. International Journal of Operations \& Production Management, 23(2), 213-229. In: Hyland P, Ferrer M, Santa R, Bretherton P (2009): Performance measurement and feedback in a public sector program, In: Soosay C, O'Neill P, Prajogo D (Eds.): Proceedings of the 7th ANZAM Operations, Supply Chain and Services Management Symposium, 8 - 10 June, Adelaide, Australia

Kitchen H (2006): A State of Disrepair: How to Fix the Financing of Municipal Infrastructure in Canada, Commentary - C.D. Howe Institute, p. 0_1, Dec 2006

Leng \& Shepherdson (2000, p. n.p.) in: James P (2005): Knowledge asset management - the strategic management and knowledge management nexus, DBA thesis, Southern Cross University, Lismore, NSW 
Love, P., Fong, P., \& Irani, Z. (2005). Management of Knowledge in Project Environments. Oxford: Elsevier/Butterworth-Heinemann.

Luffman G, Lea, E, Sanderson S, Kenny B (1996): Strategic Management - An analytical introduction, 3. Edition, Blackwell

Mardiasmo D, Tywoniak S, Brown K, Burgess K (2008): Asset Management and Governance - An Analysis of Fleet Management Process Issues in an Asset-intensive Organization. In: International Conference on Infrastructure Systems: Building Networks for a Brighter Future, 10 - 12 November, Rotterdam, Netherlands

Mathew A D, Ma L, Hargreaves D J (2008): Understanding data management in Asset Management: A survey. In Gao J, Lee J, Ni J, Ma L, Mathew J: Proceedings World Congress for Engineering Asset Management, pages pp. 1096-1107, Beijing, China

McGeoch, M., Brunetto, Y. and Brown, K. (2011) Current Issues In Strategic Asset Management, World Congress on Engineering Asset Management (WCAEM), Cincinnati, USA

Moore J F (1993): Predators and Prey: A New Ecology of Competition, Harvard Business Review, vol. 71, pp. 75-83, 1993

Narracott M, Bristow A (2001): Corporate governance in Australia, International Financial Law Review, p. 35, 2001

New South Wales Treasury (2004): Risk Management Guideline

Osborne S P, Brown K (2005): Managing Change and Innovation in Public Service Organizations, Routledge

Queensland Department of Environment and Resource Management (2010): Guidelines for the Review and Regular Audit of Strategic Asset Management Plans

Sustainability Victoria (2010): Annual Report

Schmidt S L, Brauer M (2006): Strategic Governance: how to assess board effectiveness in guiding strategy execution, Corporate Governance: An International Review, vol. 14, pp. 13-22, 2006

Tasmania Department of Treasury and Finance (2004): Developing Strategic Asset Management Plans

Thompson A A, Strickland A J (1999): Strategic Management: concepts and cases, 11. Edition, McGraw-Hill

Vial D, Prior M (2003): Use of Key Performance Indicators in the Planning and Management of Public Open Space. Proceedings of PLA Conference, Perth. In: Masayna V, Koronios A, Gao J, Gendron M (2007): Data Quality and KPIs: A link to be Established, In: The 2nd World Congress on Engineering Asset Management (EAM) and The 4th International Conference on Condition Monitoring Proceedings, Harrogate, United Kingdom, 11-14 June

Viljoen J, Dann S (2000): Strategic Management: planning and implementing successful corporate strategies, 3. Edition, Pearson Education Australia

Western Australia Department of Treasury and Finance (2010): Strategic Asset Management Framework - High-Level Policy 


\section{Acknowledgements}

This paper was developed within the CRC for Infrastructure and Engineering Asset Management, established and supported under the Australian Government's Cooperative Research Centres Programme. This paper is produced in collaboration with the Australian Asset Management Collaborative Group (AAMCoG). 